\title{
O gótico no livro Literatura Brasileira: em diálogo com outras literaturas e outras linguagens
}

\section{The gothic in the book Literatura Brasileira: em dialogo com outras literaturas e outras linguagens (Brazilian Literature: in dialogue with other literatures and other codes)}

Márcio Alessandro de Oliveira Universidade do Estado do Rio de Janeiro Rio de Janeiro, Rio de Janeiro, Brasil

Resumo: Assumindo uma hipótese segundo a qual os manuais escolares podem estar em dia com o conhecimento científico tanto quanto os textos de divulgação científica, este trabalho estuda a presença do gótico no manual mencionado no título deste trabalho. A intenção é saber como o gótico, entendido como estética e gênero, comparece no discurso didático e de que modo (implícito ou explícito) aparece tal estética. O discurso didático de William Cereja e Thereza Cochar Magalhães pode variar em novas edições, conforme a Ecdótica, sem deixar de ser condicionado pela ideologia, como postula a Análise do Discurso, ramo em que William Cereja fez doutorado. Assim, delimita-se o gótico, para saber se foi "resgatado". O resultado da investigação é apresentado após a enumeração de passagens do texto de apresentação e dos dizeres que giram em torno de alguns literatos escolhidos pelo manual, como Álvares de Azevedo e Augusto dos Anjos. Em última análise, o objetivo deste artigo é investigar o tratamento dispensado à estética gótica, a cuja prosa $\mathrm{o}$ compêndio dedica um capítulo inteiro.

Palavras-chave: Gótico. Manual escolar. Tratamento. Representação.

\begin{abstract}
Assuming a hypothesis that textbooks can be up to date with scientific knowledge as well as texts of scientific dissemination, this work studies the presence of Gothic in the manual mentioned in the title of this work. The intention is knowing how Gothic, understood as aesthetics and gender, appears in didactic discourse and in what way (implicit or explicit) appears such aesthetics. The didactic discourse of William Cereja and Thereza Cochar Magalhães can vary in new editions, according to Ecdotic, while being conditioned by ideology, as postulated by Discourse Analysis, the branch in which William Cereja did a doctorate. Thus, the Gothic is delimited, to know if it was "rescued". The result of the investigation is presented after the enumeration of passages of the text of presentation and of the sayings that revolve around some writers chosen by the manual, like Âlvares de Azevedo and Augusto dos Anjos. Ultimately, the purpose of this article is to investigate the treatment of Gothic aesthetics, to whose prose the compendium devotes an entire chapter.
\end{abstract}

Keywords: Gothic. Textbook. Treatment. Representation.

\section{INTRODUÇÃO}

Tendo em vista as observações de Jerrold Hogle, para quem obras artísticas e literárias podem variar em seu teor de goticismo, indo de "ocasionalmente góticas" a "altamente góticas" (HOGLE, 2002, p. xxi), buscamos aqui compreender como o Gótico comparece no manual Literatura brasileira em diálogo com outras literaturas e outras linguagens, de

* Estudante de mestrado na Universidade do Estado do Rio de Janeiro. Email: marciogaldino2010@hotmail.com. 
William Roberto Cereja e Thereza Cochar Magalhães, que é destinado ao Ensino Médio. Tais autores têm grande presença nos livros didáticos da área de Letras e suas obras são amplamente adotadas nas redes públicas do ensino.

Como no meio acadêmico se realizam pesquisas cujo objeto de estudo é o gótico, aqui entendido como/enquanto estética/poética da modernidade, assim como o Barroco, o Simbolismo e o Modernismo, este artigo se debruça sobre o tratamento dispensado a ele, que, de acordo com o supracitado Companion, tem forte apelo de massa junto ao público. Devido à massificação e comercialização de livros sobre bruxos e vampiros, dirigidos inevitavelmente a leitores que ainda se encontram nos Ensinos Fundamental e Médio, supõe-se que houve tempo para os manuais absorverem, talvez numa escala mais modesta, o que já se descobriu sobre o tema.

Evidenciando que o gótico tem forte apelo visual desde a arquitetura até a ekphrasis de sua diegese, percebemos a necessidade de observar a postura do manual diante da imagem e da sua relação com a literatura. Por isso, a análise das fontes primárias se resume não só ao estudo de trechos recortados do livro-texto e das referências da esfera acadêmica (como o EDTL), mas também ao emprego de uma metodologia que tenta buscar subsídios na Análise do Discurso de linha francesa; destarte, analisam-se não só os recortes do capítulo referente ao gótico ou a autores românticos ou simbolistas, mas também os do prefácio, em que os autores delimitam seu projeto didático. Para isso, assume-se o princípio de que uma escolha de palavras nunca é neutra e que a imagem tenta resgatar uma memória, sendo ambos os signos (o linguístico e o visual) ideologicamente condicionados. É por meio da análise do discurso didático que é possível saber se o manual inferioriza o gótico e as imagens.

Escolheu-se a edição de 2009, a mais atual disponível, porque, de acordo com os preceitos da Ecdótica, a mais atual corresponde à vontade de seus autores (cf. AMBROSOLI e MENDES, 2014, p.X).

O manual tenta dialogar com outras artes que não a literária. Sendo assim, a hipótese deste trabalho é a de que ele possa ter "resgatado" o gótico, o que o deixa ainda mais próximo do Barroco. A estética gótica, porém, ainda é, mesmo que por práticas discursivas de pessoas que o criticam inconscientemente, marginalizada e tão inferiorizada quanto a imagem, fato que a aproxima ainda mais da literatura/ficção de massa.

\section{HIERARQUIZAÇÃO}

Manuel da Costa Honorato, professor brasileiro oitocentista, revela um pensamento grafocêntrico ao postular a superioridade da poesia sobre as outras modalidades da arte num manual escolar: "A poesia é superior à pintura e à música, porque é a verdadeira arte do espírito, que se exprime pela palavra" (HONORATO, 1879, p. 201 apud GENS, 2005). O autor continua a discorrer em tom elogioso sobre a poesia: " [...] visto que tem por instrumento a palavra, reúne e resume as maneiras de expressão e as vantagens de outras artes" (Idem, ibidem). O professor Armando Gens, no artigo O poema como peça de exposição, fornece explicações com que se coadunam os trechos de Honorato: 
De acordo com a legislação exposta no manual, a prevalência da poesia sobre as demais modalidades da arte consistia no fato de que a arquitetura, a escultura, a música e a pintura dirigiam-se imediatamente aos sentidos, enquanto a poesia, por meio da palavra, destinavase indiretamente aos sentidos, e diretamente à imaginação e ao espírito.

Em última análise, Honorato proclama a superioridade de uma arte verbal sobre artes visuais na época em que a retórica e a poética praticamente dão lugar ao que se encontra hoje nos manuais de literatura brasileira: uma literatura nacional (cf. SOUZA, 2014, p. 25). ${ }^{1}$ A pretensa superioridade da arte literária, em que é possível incluir a prosa de ficção, posto que o romance ascende como arte e chega a ser promovido a herdeiro da epopeia ${ }^{2}$, sobre a arte visual denota inegável relação com o pensamento classicista, pois, de acordo com o texto Introdução, que Sergio Rouanet registra na edição de Origem do Drama Barroco Alemão, a alegoria, que no barroco alemão estava "[...] à altura da violência dos acontecimentos históricos" (MATOS, 2010, p. 37), sempre foi identificada com o visual: "Essa distinção, pela qual a alegoria é vista como uma forma essencialmente antiartística, como uma simples técnica de ilustrar, visualmente, uma ideia abstrata, deu origem a toda uma série de equívocos, e foi rejeitada, com razão, por Benjamin" (ROUANET, 1984, p. 37, destaques nossos).

Infere-se que essa postura diante do visual é um derivado da cultura judaico-cristã, fortalecida pelo platonismo, uma vez que tanto este como aquela inferiorizam o corpo em relação ao espírito. Até hoje, numa discussão acirrada, não é difícil ouvir alguém perguntar, em tom grosseiro, "Quer que eu desenhe?". Contudo, é preciso considerar o quanto o pensamento grafocêntrico de Honorato pode afetar, por exemplo, a recepção da arquitetura gótica, a qual demonstra o caráter visual dessa estética em sua modalidade escrita. Ao contrário do que queria Vasaria, tal arquitetura não era alemã ${ }^{3}$, mas sim nascida

\footnotetext{
${ }^{1}$ Roberto Acízelo de Souza (2014, p. 25) declara: “[...] nunca existiu, por exemplo, retórica francesa ou retórica alemã, mas simplesmente retórica; nem poética espanbola ou poética italiana, mas tão somente poética". O mesmo autor também afirma: "[...] só a partir do século XIX é que a perspectiva nacionalista se impõe nos estudos literários, tornando-se de resto indissociável da própria definição da história da literatura como disciplina" (p. 26). Como se sabe, até hoje os manuais de literatura dividem-na em períodos ou estilos de época separando as obras brasileiras das de Portugal. Curiosamente, "Estilo de época é o reconhecimento estético da representação de uma posição de classe diante de conflitos ideológicos" (SODRÉ, 1978, p. 98). Essa última consideração vai ao encontro do que diz Souza (2014, p. 60) a respeito da história da literatura como disciplina: "[...] a aliança entre história da literatura e ideologia nacionalista constituiu providência conceitual fundadora da disciplina, que se define exatamente como assunção da concepção romântica de literatura como expressão da nacionalidade". Naturalmente, isso permite que se entenda a separação da literatura nacional da escola como condição das "comparações entre literaturas" (WELLEK e WARREN, 2003, p. 49), que "[...] tendem a restringir-se a problemas externos de fontes e influência, reputação e fama", tendência presente nos manuais analisados neste artigo.

${ }^{2}$ Segundo Muniz Sodré (1978, p. 67), “[...] o romance-arte só poderia ser visto como uma conquista para a verdade da consciência".

${ }^{3}$ A respeito do barroco arquitetônico e de sua transposição para o terreno literário, Sergio Rouanet (1984, pp. 25-6) presta as informações seguintes: "Desde Wölfflin, em 1888, o barroco arquitetônico já era visto como um estilo próprio, distinto da Renascença, e com direitos iguais à investigação crítica. Sua transposição para o terreno literário já havia ocorrido, em parte por indicações do próprio Wölfflin, e o sentido negativo original atribuído a expressões mais antigas, como gongorismo, concettismo, marinismo e eufuísmo, já estava francamente superado. Assim, quando Benedetto Croce, em 1925, defendeu a reintrodução do termo
} 
"com a arquitetura religiosa da Normandia e da Borgonha, durante o séc. XII" (BARSA, 1991, p. 281). Note-se o adjetivo religiosidade: é uma das características do Barroco tanto quanto as tensões geradas por opostos ou extremos. É possível encarar a arquitetura gótica como arte medieval, ${ }^{4}$ porque

[...] após os minuciosos estudos de ensaístas como Mâle, Focillon, Dvorák e outros, entendese por gótico o estilo de arte medieval que, tendo-se originado por volta de 1150, em França, transformar-se-ia em estilo internacional, durando até 1420 na Itália e até 1500 nos países setentrionais. O estilo gótico é, antes de tudo, um estilo arquitetônico; mas o adjetivo gótico é empregado também para caracterizar a pintura e a escultura do período. (Enciclopédia Barsa, 1991)

Se a literatura serve-se da realidade externa e do que a civilização oferece a quem a produz (cf. CANDIDO), é arrazoado supor que a arquitetura gótica, identificada com o medieval, influenciará a ekphrasis, a imagética, da literatura gótica e seu locus horribilis. Somadas às considerações de Honorato, a mentalidade classicista e as relações com a arquitetura permitem que qualquer compêndio de literatura nacional que proponha o diálogo entre a literatura e outras artes reverbere o logocentrismo de Honorato e o pensamento classicista.

\section{O GÓTICO COMO ESTÉTICA E GÊNERO}

A despeito da crise dos gêneros, ainda se faz necessária a taxonomia para os livros didáticos. A respeito do gótico, sua modalidade literária é inaugurada em 1764, na Inglaterra, com o romance O Castelo de Otranto, de Horace Walpole (1717-1797). Segundo verbete de Maria Leonor Machado de Sousa, presente no E-Dicionário de Termos Literários, aos aspectos do sobrenatural somam-se algumas considerações em torno do romance gótico,

em que se procura despertar terror. O termo "gótico" tem a ver com o cenário, um castelo ou outro edifício imponente que pudesse considerar-se [sic] medieval [...]. Também a época em breve deixou de ser antiga, mantendo dela apenas o cenário: castelos, torres ou conventos arruinados, por onde passavam heróis, heroínas e vilões dos tempos modernos [...].

em seu sentido original - o barroco como uma das variedades do feio, uma varietà deI brutto - essa opinião já era uma extravagância a contracorrente, ultrapassada pela nova sensibilidade, e o próprio Croce não hesitou, mais tarde, em utilizar apalavra como categoria estética valorativamente neutra".

${ }^{4}$ A esse respeito é preciso entender que o conceito de arte é variável por depender da ideologia, razão pela qual é interessante o dizer de Muniz Sodré (1978, p. 67): “A arte (com sua irredutibilidade bem demonstrada) aparece no ensaio de Heidegger como uma essência, um Absoluto, acima da diferença das classes sociais. Dentro desta perspectiva, o romance-arte só poderia ser visto como uma conquista para a verdade da consciência". Contudo, "[...] quando um crítico como Alain Badiou afirma que 'arte não é ideologia', por denunciar o reflexo deformado das contradições reais de existência, é preciso corrigi-lo, reafirmando a literatura como uma formação ideológica, determinada historicamente, capaz de encenar toda e qualquer contradição - menos aquela em que está diretamente apoiada. Sem o seu modo específico de poder, a literatura não poderia reconhecer-se como arte literária" (idem, ibidem, p 72). Além disso, o que vale para a arte literária vale para as outras em termos de reconhecimento e definição do que é e o que não é arte. 
Portanto, há uma forte relação com o cenário e a arquitetura, o que equivale a dizer que o gótico é de caráter visual na ekphrasis de sua diegese. Para Hugo Matos, por gótico se entende excesso, representações de trevas, ruínas, alteridade e transgressão. De acordo com ele, o Gótico não apenas transparece em várias obras literárias dos finais do século XVIII e início do século XIX, mas igualmente em obras dos séculos XX e XXI.

\section{O GTICO NO LIVRO LITERATURA BRASILEIRA: EM DIÁLOGO COM OUTRAS LITERATURA E OUTRAS LINGUAGENS}

\subsection{UMA ANÁlISE DISCURSIVA DA PROPOSTA PEDAGÓGICA DO MANUAL}

A quarta edição do livro de Cereja e Cochar data de 2009. ${ }^{5}$ Esse manual apresenta dois ISBNs: ${ }^{6}$ um do livro do aluno, o outro do livro do professor. A apresentação da edição de 2005 é idêntica à da edição de 2009: ambos os textos de abertura contêm um quê de culto da arte da palavra, que se identifica com o logocentrismo, em contraste com as imagens; além disso, dizem que o sentido profundo do texto literário tem de ser extraído, e não produzido na interação. A atenção voltada a essas constatações tem razão de ser: 1. o gótico conta com uma modalidade visual: a arquitetura; 2. Cereja era doutorando em Análise do Discurso, disciplina segundo a qual o sentido é um efeito, um produto, e não um saber acabado que tenha de ser extraído.

O manual é assim dividido: começa com um texto de apresentação dirigido ao aluno (o leitor implícito) seguido do sumário, que apresenta doze unidades, dentro das quais se situam os capítulos, e dentro destes são distribuídos os estilos de época. O capítulo final de cada unidade intitula-se Diálogos e gira em torno de artes não literárias.

É preciso atentar para certos detalhes, a começar pelo supracitado texto de apresentação, em que fica dito (2009, p. 3): "Neste nosso mundo moderno ou pósmoderno, que privilegia a imagem e a rapidez das informações, parece não haver espaço para a palavra, para a leitura e para o estudo da literatura. ${ }^{7}$ Essa impressão, contudo, não é verdadeira". Esboça-se o caráter não hierárquico e não reducionista, mas logo se desmancha a partir de uma pergunta que é puramente retórica:

E por que alguém se interessaria em estudar literatura nos dias de hoje?

\footnotetext{
${ }^{5}$ A ficha catalográfica não registra a data de publicação da primeira edição.

${ }^{6}$ Foi utilizada apenas a edição destinada a alunos.

7 É pertinente o sugestivo título do livro de Joel Rufino: Quem gosta de literatura não estuda literatura. Obviamente, o mote do título vai de encontro à proposta didático-ideológica do compêndio, o qual pode assumir uma determinada posição didático-ideológica para agradar à instituição escolar, e não necessariamente para corresponder às intenções ou convicções dos próprios autores.
} 
Literatura é a arte da palavra. Estudá-la equivale a compreender a evolução do pensamento e dos sentimentos humanos através da arte; é uma forma de aguçar nossa sensibilidade e nossa percepção crítica, de lutar contra os fenômenos da alienação, da fragmentação e da desumanização a que estamos sujeitos no mundo atual.

Observe-se que os autores falam em alienação e desumanização, mas antes falam em evolução, identificável com o progresso celebrado pelo racionalismo e pelo positivismo. No quarto parágrafo, apresentam mais razões para o estudo de literatura:

Estudar literatura é enfrentar o desafio de ler os grandes textos literários criados pela humanidade, extrair-lhes o sentido mais profundo e perceber de que forma estão relacionados com o momento em que foram concebidos. [...] Estudar literatura é perseguir os diálogos que o homem criou e vem criando consigo mesmo em diferentes tempos e espaços, como meio de dizer não ao isolamento e à solidão.

$\mathrm{Na}$ opinião de Cereja e Cochar, existe arte da palavra, mas não explicitam as relações de poder que tal arte implica; também existe humanidade, mas não se menciona a inspiração do gênio ou do vate, comum no tempo do Romantismo, em que o individualismo era necessário e afirmado, e não negado. Se a atividade de ler, "em suas origens, era individual e reflexiva (em oposição ao caráter coletivo, volátil e irrecuperável da oralidade de poetas e contadores de histórias)" (LAJOLO, 2002, p. 105), e a apreciação da arte literária é um não ao senso comum, em que sentido ler literatura é dizer não à solidão? Tratar-se-ia do comunicando (leitor) que entra em contato com um produto da civilização, e não apenas com o eu? Seria uma negação do solepsismo (existência solitária) do leitor que reescreve o texto ao lê-lo?" Os autores sustentam que ler literatura é "ser diferente da maioria, que se limita ao senso comum veiculado pelos meios de comunicação de massa". ' Neste caso, como ficam os leitores que leem apenas best-sellers? Infere-se que a literatura, para o manual, é formada apenas pelos "grandes" textos, o que significa que ela se reduz ao cânone (seja ele qual for). Diante disso e da falta de referências bibliográficas, tão ausentes quanto a menção ao estranhamento, de que falam os formalistas russos, e à literaturidade, fica evidente a posição subalterna reservada pelo livro didático à série Harry Potter (1997-2007), da inglesa J. K. Rowling (1965), e ao romance O Código Da Vinci (2005). "Livros como esses", indagam os autores de modo meramente retórico, "podem ser uma boa porta de entrada para a leitura, um meio de despertar nas pessoas o interesse pela literatura?” (p. 12). Pelo visto, são aceitáveis, desde que sejam tão só uma iniciação para os escritos dos "grandes" autores, o que é curioso para um livro didático que dedica uma capítulo inteiro à prosa gótica, que, segundo Michael Gamer, foi identificado com a "baixa" e "alta" culturas (2002, pp. 98-9). Trata-

${ }^{8}$ De acordo com Antonio Cândido, “[...] a arte pressupõe algo diferente e mais amplo do que as vivências do artista. Estas seriam nela tudo, se fosse possível o solipsismo; mas na medida em que o artista recorre ao arsenal comum da civilização para os temas e formas da obra [...], é impossível deixar de incluir na sua explicação todos os elementos do processo comunicativo" (2000, p. 21 apud MORAES, 2013, p. 2).

${ }^{9}$ Durante as aulas da disciplina Literatura e Outras Mídias, do mestrado acadêmico em Estudos Literários do Programa de Pós-Graduação em Letras e Linguística, da UERJ, campus de São Gonçalo, foi mencionada a seguinte frase: "Massa é todo o mundo menos eu". 
se de uma forma de hierarquizar a literatura de massa. ${ }^{10}$ Entretanto, não se acham vestígios de tal distinção.

Além disso, a humanidade a que se referem os autores é abstração, e, no dizer de Paulo Freire, "humanidade como abstração é coisíssima nenhuma" (2017), e remonta ao humanismo e ao antropocentrismo, reafirmados pela burguesia ascendente do século XVIII. O manual apregoa a importância do estudo da literatura. "Também”, escreve Terry Eagleton, "é essa a debilidade da argumentação humanista" (2006, p. 312), que acredita que a literatura possa fazer dos seres humanos pessoas melhores (o que configura uma proposta educadora), mas “só pode explicar o que entende por uma 'pessoa melhor' nos termos mais limitados e abstratos" (idem, ibidem, p. 313).

Ainda no que concerne à proposta do manual, faz-se mister salientar que é repleto de imagens, como a pintura, o que reforça a aparência de diálogo com as outras modalidades da arte. Uma das imagens apresentadas é uma reprodução do quadro $A s$ vaidades da vida humana (1645), de Harmen Steenwyck (p. 133). Na capa, por exemplo, aparecem imagens dos números 7 e 365 da revista Para Todos, embora, conforme já ficou evidenciado, o texto de apresentação indique que os autores se preocupam com o lugar da literatura num mundo de imagens, o que talvez sugira uma negação freudiana. Essa negação é reforçada diante do que Cereja e Cochar afirmam sobre o livro O xangô de Baker Street: "Em 2001, o livro de Jô Soares deu origem ao filme de mesmo nome, dirigido por Miguel Faria Jr" (p. 321). O termo origem chama a atenção por ser identificável com o logocentrismo, incompatível com uma prosa de ficção que ecoa a ficção de Conan Doyle, autor de romances policiais, gênero inaugurado por Edgar Allan Poe (1809-1849), autor gótico por excelência.

Não é neutra a escolha dos termos grandes textos literários, massa e origem: revelam uma estrutura de pensamento.

\subsection{O CAPÍTULO DEDICADO À PROSA GÓTICA}

Dentro da Unidade 6, "O Romantismo. A prosa”, encontra-se o Capitulo 21, intitulado A prosa gótica - o penúltimo da unidade — sucedido pelo Capitulo 22, Diálogos, em que se estabelecem relações entre o cinema contemporâneo e a tradição gótica, cuja persistência atravessa a história moderna com tantas mudanças e variações de modo curioso por mais de 250 anos (cf. HOGLE, 2002, p. 2). ${ }^{11}$ Ocupa oito páginas (das quais duas e meia são

\footnotetext{
${ }^{10}$ Pontuam os professores Cereja e Cochar que Os sofrimentos do jovem Werter provavelmente "foi o primeiro best-seller da literatura ocidental" (p. 193).

${ }^{11}$ Um dos objetivos do Cambridge Companion é o de "[...] explicar os motivos pelos quais a persistência do Gótico atravessa a história moderna e como e por que houve tantas mudanças e variações de modo curioso por mais de 250 anos" (HOGLE, 2002, p. 2). No texto de partida: "Our objectives here are to explain the reasons for the persistence of the Gothic across modern history and how and why so many changes and variations have occurred in this curious mode over 250 years".
} 
dedicadas apenas a Álvares de Azevedo), o que faz dele o maior da sua unidade. Machado de Assis, por exemplo, ocupa o livro da página 305 a 312.

Abrindo o capítulo com uma fotografia do filme $A$ noiva cadáver, Cereja e Cochar descrevem a literatura gótica nos termos seguintes (p. 262):

Contrapondo-se aos valores racionalistas e materialistas da sociedade burguesa, certos escritores do Romantismo criaram uma literatura fantasiosa, identificada com um universo de satanismo, mistério, morte, sonho, loucura e degradação. Trata-se da literatura de tradição gótica - conhecida também como maldita —, que até hoje encontra adeptos da literatura, na música, no cinema e no estilo de vida.

Assinalando a sintonia da prosa de Álvares de Azevedo com Byron, Baudelaire e Poe (o que confirma a identificação de fontes e influências, conforme WELLEK e WARREN, 2003, p. 49), William Cereja e Tereza Cochar afirmam que os principais representantes românticos do gótico são Álvares de Azevedo e Bernardo Guimarães (autor não explorado). O gótico literário, considerado marginal ou maldito, era assim classificado por estar à margem dos padrões do próprio Romantismo e da sociedade burguesa (p. 262). Também atribuem traços góticos a literatos posteriores, como o francês Mallarmé, Cruz e Sousa, Alphonsos de Guimaraens e Augusto dos Anjos, além do dramaturgo Oscar Wilde, cujos nomes são sucedidos por referências ao heavy metal e ao punk, estilos musicais.

Poemas de Azevedo estão no Capítulo 15 (pp. 206-18), "O Ultrarromantismo”, em que se encontram os poemas Soneto, Poema do frade, Ideias intimas e É ela! É ela! É ela! É ela!, com que se intercala um comentário de Antonio Cândido dentro de uma pequena coluna de fundo roxo intitulada Sexo, satanismo e rebeldia (p. 211).

$\mathrm{Na}$ seção intitulada Álvares de Azevedo: a prosa marginal, presente na página 263 - a mesma em que se indicam sites ${ }^{12}$ sobre subcultura ${ }^{13}$ gótica —, são destacados Noite na taverna e a peça teatral Macário. Numa hipótese que se coaduna com o que postula Antonio Cândido, para quem as vivências do autor não podem por si sós explicar o texto literário, Cereja e Cochar dizem que os contos de Noite na Taverna provavelmente não têm nenhum vínculo direto com experiências da vida do autor, morto aos 21 anos. O capítulo carece das datas de vida e morte dos autores e das datas de produção e publicação dos seus textos. As páginas 264 e 265 são preenchidas pelo Capítulo II de Noite, que contém um fio narrativo que une as suas histórias. Na seção, mencionam O Castelo de Otranto e Byron como possíveis influências de Noite, além da série em quadrinhos Sandman, de Neil Gaiman. Tal série é a "expressão máxima do gótico" nos quadrinhos (p. 264). Antes de encerrar o capítulo com um questionário de sete perguntas, uma coluna enumera filmes góticos, a saber: Nosferatu, uma sinfonia de horror (1922), de F. W. Murnau; Drácula (1931),

\footnotetext{
${ }^{12} \mathrm{Os} \quad$ endereços são estes: wmw.gothicstation.com.br, wmw.geocities.com/floresdomal/; flog.clickgratis.com.br/syb855/dat-200802; br, geocities.com/silvatextqliteratura1.btm.

${ }_{13}$ Obviamente o termo não foi cunhado pelos autores, mas já ficou dito que a escolha de palavras nunca é neutra.
} 
de Tod Browning; Nosferatu, o vampiro da noite (1979), de Werner Herzog; Drácula de Bram Stoker (1992), de Francis Ford Coppola; Blade Runner (1982), de Ridley Scott; Asas do desejo (1987), de Win Wenders; e Matrix (1999), de Andy Wachowski e Larry Wachowski.

Se o capítulo dedicado à prosa gótica não contém datas, essas foram "espalhadas" em outros. Autores como Baudelaire (1821-1867), apresentado no Capítulo 27, que trata do Simbolismo, e Cruz e Sousa têm transcritos, respectivamente, os poemas Correspondências e Violões que choram. ${ }^{14}$ Mas o que mais explicita o vínculo entre o gótico e o simbolismo é a pequena coluna intitulada Os simbolistas e os góticos, em que tal relação é exemplificada com um excerto em português de Uma temporada do inferno, do francês Rimbaud. ${ }^{15}$ Augusto dos Anjos, por sua vez, teve escolhidas as poesias Versos intimos, Psicologia de um vencido e Budismo moderno, retirados da 30a edição de Eu e outros poemas.

No que concerne ao Capítulo 22 (em que não se apresenta o poema O Corvo, que é apenas indicado como sugestão de leitura), precisamos enfatizar um dado: a menção ao romance Drácula. A seu respeito, os autores fazem comentários em que inserem referências ao livro Drácula, o homem por trás do mito, de Roberta Zugaib, e ao documentário Vampiros, a sede pela verdade, do Discovery Chanel. Contudo, destaca-se a estimativa registrada no manual: "estima-se que Drácula, de Bram Stoker, seja o segundo livro mais lido no mundo, depois da Bíblia” (2009, p. 274). Infere-se que se trataria do segundo livro mais vendido. Salientamos tal estimativa por ela reafirmar o elo entre a literatura gótica e a literatura de massa.

\section{CONSIDERAÇÕES FINAIS}

O manual de Cereja e Cochar denota a adoção de princípios oriundos do século XIX, em que se consolidou a história da literatura, substituta da retórica e da poética. Também demonstra uma visão hierarquizante devido à escolha de palavras, como grandes textos literários e origem, sendo o primeiro um termo desprovido de critérios objetivos para decidir o que seja grande e o que seja pequeno em literatura. Por isso, é preciso sugerir que adotem os termos texto de partida, texto de chegada (no caso das adaptações cinematográficas) e cânone nas páginas em que aparecem os que carregam um caráter logocentrista, apesar da variedade de imagens (reproduções de pinturas) e referências fílmicas, as quais, sob a luz da revelação dos fatores históricos e ideológicos que condicionaram a escolha de palavras do texto dirigido ao leitor implícito, confirmam o ponto de vista de Maria Helena Martins, para quem os conteúdos modernos podem esconder visões de mundo conservadoras. Essas constituem o não dito que comparece no dito e vão na contramão do poema Liberdade, de Fernando Pessoa, principalmente no que concerne ao estudo da literatura (cf. LAJOLO, 2002, p. 13). Com relação ao

\footnotetext{
${ }^{14}$ Não há bibliografia no fim do manual, mas a fonte de cada texto transcrito é declarada logo abaixo de cada um deles.

${ }^{15}$ Foi omitido o nome do tradutor no livro, o que, conforme Lia Wyler, reforça o logocentrismo e a invisibilidade do tradutor.
} 
humanismo, a humanidade a que se referem os autores é mais antropocêntrica do que antropológica por ser abstrata. Dessa forma, mesmo que inconscientemente, apagam as diferentes identidades culturais, que compõem a humanidade concreta. Tal noção de humanidade pode ser tão obsoleta quanto a premissa da extração do sentido mais profundo do texto literário, princípio que, para alguém que se enveredou pela Análise do Discurso, deve ser considerado falso e trocado por uma premissa segundo a qual o sentido é produto da interação. Afinal, o sentido não é estanque nem unívoco. Em verdade, é preciso falar em sentidos, os quais sempre podem ser outros, conquanto nem um deles possa ser qualquer um (cf. ORLANDI).

Não se trata de uma caça a "fantasmas com fogos de artifício" (LAJOLO, 2002, p. 64) que se dê na forma de acusações de parcialidade ideológica, "tão ingênuas quanto proclamações de neutralidade ideológica" (idem, ibidem), mas sim da assunção de que Literatura brasileira: em diálogo com outras literaturas e outras linguagens é linguagem e mercadoria. Portanto, identifica-se a "[...] fina malha social pela qual circulam e por via da qual se transformam em discurso e interagem socialmente" os livros didáticos. "Também como linguagem, material didático tem refolhos e avessos, silêncios e entrelinhas" (op. cit., 2002, p. 65), o que se coaduna com a necessidade de produzir um discurso didático em torno da literatura que esteja de acordo com a instituição de ensino, e não necessariamente com a sincera opinião dos autores, os quais carregam um histórico de livros didáticos comprados e distribuídos pelo Ministério da Educação. Afinal, o Ministério da Educação, o maior comprador de livros didáticos do mundo, ${ }^{16}$ precisa aprovar o livro que chega ao professor, que não é obrigado a trabalhar com um material com que não se sinta à vontade.

Contudo, os lugares-comuns relativos ao gótico não destoam do que até agora se sabe sobre ele, que, em outros manuais de Ensino Médio consultados para esta pesquisa, não dedicam tanto espaço quanto o de Cereja e Cochar, o que lhes rende um resgate da estética gótica, vista como marginal ou inferior não só numa análise diacrônica, mas também sincrônica: ocorre que, devido ao uso do termo origem e à distinção entre os "grandes" textos e os best-sellers que talvez possam despertar o interesse pela literatura como se dela eles não fizessem parte - o manual acaba por marginalizar a estética gótica, filiada à literatura de massa. Essa, a ser verdade o que dizem Cereja e Cochar, não é literatura.

Faltam-lhes as referências de textos de divulgação científica, como verbetes de dicionários de termos literários e a inclusão de autores como Lúcio Cardoso e Cornélio

\footnotetext{
${ }^{16}$ Em entrevista concedida em 26 de janeiro de 2013 ao Jornal Universitário do Pampa, Marcos Bagno declara: "Uma mesma editora produz cinco ou seis coleções de Língua Portuguesa do $3^{\circ}$ ao $5^{\circ}$ ano, por exemplo. Cada coleção com um perfil diferente: uma bem conservadora, uma que se adapta mais a escolas religiosas particulares, outra que tenta responder ao MEC, então para poder se sair bem na avaliação do PNLD... Mas vocês sabem que o MEC do Brasil é o maior comprador de livros do mundo, é uma coisa assim de não sei quantos milhões de livros comprados. Ter uma coleção aprovada é uma coisa fantástica, porque você vai vender milhares de exemplares, vai ganhar 4 ou 5 milhões de reais, 50 milhões de reais se você vender 4 ou 5 coleções. Eu conheci autores de livros didáticos que dizem que gostariam até de inovar em algumas coisas, mas as editoras não deixam porque elas sabem que existe um professorado mais conservador que não se adapta a algumas mudanças, então fica difícil".
} 
Penna. E parte disso tem razão de ser: o livro não conta com bibliografia, conquanto outro manual dos mesmos autores apresente suas fontes (como Português: Linguagens).

Em resumo, o compêndio é oitocentista e hierarquizante na medida em que periodiza a literatura do país, o que proporciona o reconhecimento de seu vínculo com o contexto histórico, negado de forma extrema pela teoria literária (cf. EAGLETON, 2006, p. 296), e revela uma estrutura de pensamento logocêntrica e humanista, mas é inovador por dedicar espaço ao gótico e às muitas imagens que o livro contém. Em última análise, o livro didático, dessa forma, criou, graças à variedade, possibilidades de construção de conhecimento.

\section{REFERÊNCIAS}

AMBROSOLI, Silvana dos Santos; MENDES, Marlene Gomes. Crítica Textual (vol. 1). Rio de Janero: Fundação Cecierj, 2014.

BARROS, Fernando Monteiro. A alegoria e o fantasma no gótico brasileiro: Cornélio Penna e Lúcio Cardoso. In: Anais do XV Encontro ABRALIC. Rio de Janeiro: UERJ, 2016, p. 2472-2482. Disponível em: http://www.abralic.org.br/anais/arquivos/2016_1490918496.pdf Acesso em: 10 ago. 2017.

CECERJA, William Roberto; MAGALHÃES, Thereza Cochar. Literatura brasileira: em diálogo com outras literaturas e outras linguagens. 4. ed. reform.. São Paulo: Atual, 2009.

EAGLETON, Terry. Teoria da literatura: uma introdução. Trad. Waltensir Dutra. São Paulo: Martins Fontes, 2006.

JORGE, Greice Kelly; BAGNO, Marcos. Entrevista exclusiva com Marcos Bagno. Disponível em: http://www.junipampa.net/2013/01/entrevista-exclusiva-com-marcosbagno.html. Acesso em: 19 out. 2017.

FARACO, Carlos Emílio; MOURA, Francisco Marto. Lingua e Literatura. 9. ed. São Paulo: Editora Ática, 1999.

FREIRE, Paulo. Pedagogia da autonomia. São Paulo: Paz e Terra, 2011.

- Pedagogia do oprimido. São Paulo: Paz e Terra, 2011.

- Pedagogia da Tolerância. São Paulo: Paz e Terra, 2017.

GENS, Armando. O poema como peça de exposição. In: Revista Texto Poético, Vol. 3 (2o sem-2005).

GAMER, Michael. Gothic fictions and Romantic writing in Britain. In: HOGLE, Jerrold E. (org.). The Cambridge Companion to the Ghotic Fiction. UK: Cambridge University Press, 2002.

HOGLE, Jerrold E.. Introduction: the Gothic in western culture. In: (org.) et al.

The Cambridge Companion to the Ghotic Fiction. UK: Cambridge University Press, 2002. 
INFANTE, Ulisses. Curso de Literatura de Lingua Portuguesa (volume único). São Paulo: Scipione, 2001.

LAJOLO, Marisa. Do mundo da leitura para a leitura do mundo. 6. ed. São Paulo: Editora Ática, 2002.

MARTINS, Maria Helena. O que é leitura. 19. ed. São Paulo: Brasiliense, 2006, pp. 25-6. MORAES, Anita M. R.. Aula 11: A literatura e a vida social. In: et al. Teoria da Literatura II. Rio de Janeiro: Fundação Cecierj, 2013.

MOREIRA, Adriana Leite. Crítica Textual nos livros didáticos de língua portuguesa. In: SOLETRAS, Ano X, No 19, jan./jun.2010. São Gonçalo: UERJ, 2010 - Suplemento 119. PESSOA, Fernando. Liberdade. In: Obra Poética. 9. ed. Rio de Janeiro: Nova Aguilar, 1986.

ROUANET, Sergio Paulo. Apresentação. In: BENJAMIN, Walter. Origem do drama barroco alemão. Trad. Sergio Rouanet. São Paulo: Brasiliense, 1984.

SOUZA, Roberto Acízelo de. Panorama dos Estudos Literários. In: - História da literatura: trajetória, fundamentos, problemas. São Paulo: É Realizações, 2014.

TUFANO, Douglas. Estudos de literatura brasileira. 4. ed. rev. e ampl. São Paulo: Moderna, 1988.

WELLEK, Rene; WARREN, Austin. Teoria da literatura e metodologia dos estudos literários. São Paulo: Martins Fontes, 2003. 